\title{
Estrutura florestal e serapilheira acumulada predizem a velocidade da dinâmica demográfica em florestas secundárias da Mata Atlântica ${ }^{1}$
}

\author{
Cilmar Antonio Dalmaso ${ }^{2}$; Marcia Cristina Mendes Marques ${ }^{3}$; Pedro Higuchi ${ }^{4}$; Victor Pereira \\ Zwiener $^{5}$; Renato Marques ${ }^{6}$
}

Resumo: O conhecimento dos fatores preditivos da dinâmica demográfica de florestas secundárias é útil para planejar estratégias de recuperação de áreas degradadas, estimar a produção de biomassa e para subsidiar o planejamento da utilização racional de recursos. O objetivo deste estudo foi investigar possíveis fatores bióticos e abióticos que predizem taxas de dinâmica demográfica da vegetação secundária da Mata Atlântica. Para isto, em seis florestas, que variaram em idade desde a última perturbação $(25,60,75,90$ e mais de 100 anos), a ordenação por PCA das taxas demográficas (mortalidade, recrutamento, rotatividade em abundância, perda em área basal, ganho em área basal e rotatividade em área basal) foi utilizada como variável resposta em uma árvore de regressão. Como possíveis fatores preditivos foram utilizados: declividade, variáveis químicas do solo em diferentes profundidades, parâmetros da estrutura florestal, quantidade de serapilheira acumulada e padrões espaciais. A árvore de regressão revelou que variações locais nos padrões dinâmicos foram melhor preditas pela estrutura florestal e pela quantidade média de serapilheira acumulada. Locais com estrutura menos desenvolvida em relação ao diâmetro máximo, altura máxima e área basal ocorreram nas florestas mais jovens (25 anos) e em clareiras das florestas mais antigas (com 90 e 100 anos), onde foram observadas as maiores taxas de dinâmica demográfica. Áreas com estrutura mais desenvolvida foram frequentes em todas as florestas, independente da idade pósperturbação. Nestas áreas, as mudanças foram mais lentas e a quantidade de serapilheira acumulada sobre o solo foi inversamente proporcional à rotatividade de árvores e de área basal.

Palavras - chave: Floresta Ombrófila Densa Submontana; Sucessão ecológica; Taxas demográficas; Atributos químicos do solo

\section{Forest structure and litter predict the speed of demographic dynamics in secondary forests of the Atlantic Forest}

\begin{abstract}
The knowledge of predictive factors related to the demographic dynamics of secondary forests is useful plan strategies for recovery of degraded areas, estimate the production of biomass and to subsidize the planning for rational use of resources. The aim of this study was to investigate possible biotic and abiotic factors that predict rates of demographic dynamics in second-growth vegetation of the Southern Atlantic Forest. We applied a PCA on data from six forests which varied in age from the last disturbance $(25,60,75,90$ and more than 100 years-old) ordering of demographic rates (mortality, recruitment, abundance turnover, loss in basal area, basal area gain and basal area turnover), and used its ordination as response variable in a regression tree. As possible predictive factors were used: slope, soil chemical variables at different depths, forest structure parameters, amount of litter and spatial patterns. The regression tree revealed that the dynamics rates were better predicted by the forest structure and by the average amount of litter. Sites with a less developed structure in relation to maximum diameter, maximum height and basal area occurred in the youngest forests ( 25 years-old) and in clearings of the oldest forests (90 and 100 years-old), where the highest rates of demographic dynamics were observed. Areas with more developed structure were frequent in all forests independent of post-disturbance age. In these areas, the changes were slower and the amount of litter on the ground was inversely proportional to trees and basal area turnover.
\end{abstract}

Keywords: Submontane Dense Ombrophilous Forest; Ecological succession; Demographic rates; Soil chemical attributes

\footnotetext{
${ }^{1}$ Recebido em 20.06.2019 e aceito para publicação como artigo científico em 16.08.2019.

${ }^{2}$ Eng. Florestal, M.Sc. Doutorando em Engenharia Florestal, Universidade Federal do Paraná, PR, Brasil. E-mail: <cilmard@ gmail.com>

${ }^{3}$ Bióloga, Dra. Professora Titular da Universidade Federal do Paraná, PR, Brasil. E-mail: <marciaguanandi@gmail.com>

${ }^{4}$ Eng. Florestal, Dr. Professor Associado VI da Universidade do Estado de Santa Catarina (UDESC), SC, Brasil. E-mail: <higuchip@gmail.com>

${ }^{5}$ Biólogo, Dr. Professora da Universidade Federal do Paraná, PR, Brasil. E-mail: 〈vzwiener@gmail.com>

${ }^{6}$ Eng. Florestal, Dr. Professor Associado IV na Universidade Federal do Paraná, PR, Brasil. E-mail: <rmarques1961@ gmail.com>
} 


\section{Introdução}

A dinâmica da vegetação florestal reflete interações complexas de eventos de perturbação (CHAZDON, 2003) e requer uma compreensão de como os outros componentes interagem, influenciando em escala regional e local (NORDEN et al., 2015). Na Mata Atlântica, as taxas de dinâmica demográfica apresentam relação com os parâmetros estruturais da vegetação e da paisagem (GROSS et al., 2018); com a sucessão (MACHADO e OLIVEIRAFILHO, 2010); cobertura do dossel; atributos químicos do solo (soma de bases) (SALAMI et al., 2014) e variações topográficas (MARQUES et al., 2009). Além disso, o crescimento das árvores é potencialmente afetado por atributos químicos do solo (CARDOSO et al., 2012), sendo que variações em pequena escala podem influenciar trajetórias sucessionais, principalmente onde a vegetação se desenvolve sobre solos com baixa fertilidade (MARTINS et al., 2015). É em pequena escala também que ocorrem as relações mutualistas entre macro e micro-organismos, que sob as condições de alta temperatura e umidade, aumentam muito a atividade biológica sobre a dinâmica da matéria orgânica (LAVELLE et al., 1993), causando aumento da decomposição da serapilheira e da mineralização de nitrogênio, nutriente limitante ao crescimento das florestas tropicais (VITOUSEK e HOWARTH, 1991).

Estimativas recentes mostram que as florestas nativas representam $26 \%$ da cobertura do bioma Mata Atlântica (REZENDE et al., 2018), proporção abaixo do limiar recomendado para manter a integridade de diferentes grupos taxonômicos (BANKSLEITE et al., 2014). Além disso, por se tratar de um hotspot intensamente fragmentado (RIBEIRO et al., 2009) e antropizado (REZENDE et al., 2018), apresenta alta vulnerabilidade às mudanças. Tal situação requer políticas públicas com estratégias de monitoramento e predição das mudanças, pois importantes serviços ecossistêmicos estão ameaçados.

O trecho de floresta onde este estudo foi realizado está inserido no segundo maior remanescente de Mata Atlântica contínua do país (RIBEIRO et al., 2009), no litoral do Paraná, e é caracterizado por um mosaico de vegetação de florestas secundárias com diferentes idades pós perturbações naturais e antrópicas. Um conjunto de parcelas permanentes de florestas com diferentes idades foi monitorado por dois inventários com intervalo de 10 anos. Neste trabalho foi testada a hipótese de que variações locais nos padrões dinâmicos das assembleias de árvores podem ser preditas por fatores ambientais como inclinação do terreno, quantidade de serapilheira acumulada, atributos químicos do solo em diferentes profundidades, estrutura da floresta e padrão espacial em diferentes escalas.

$\mathrm{O}$ objetivo deste trabalho foi investigar quais fatores bióticos e/ou abióticos predizem as taxas de dinâmica demográfica da vegetação secundária da Floresta Atlântica Submontana, no litoral do Paraná.

\section{Material e métodos}

\section{Área de estudo e desenho amostral}

O estudo foi realizado na Reserva Natural Guaricica localizada no município de Antonina, estado do Paraná, em área de formação natural da Floresta Ombrófila Densa Submontana no bioma da Mata Atlântica. O clima da região é subtropical úmido com verões quentes e temperados, classificado como $\mathrm{Cfa}$, segundo Köppen-Geiger, com uma precipitação média anual de $2.545 \mathrm{~mm}$ (FERRETTI e BRITEZ, 2006). A matriz florestal predomina na paisagem devido à existência de outras Unidades de Conservação que contribuem para as boas condições ambientais da região. Esta pesquisa buscou analisar dados de seis faixas etárias com floresta secundária no processo de regeneração natural (Tabela 1).

As idades das florestas foram estimadas por meio de entrevistas com proprietários de terras e moradores antigos, imagens de satélite ou fotografias aéreas e contagens de anéis de 
árvores (DONHA, 2016). O uso do solo ou cobertura vegetal, em tempos passados, variou entre agricultura com solo exposto e extração seletiva de madeira, combinada com extração de palmito. Na região do entorno sempre predominou a cobertura florestal nativa; e o uso antrópico mais expressivo e impactante para a regeneração foi à criação de bubalinos, em pastagens com herbáceas de espécies naturalizadas (incluindo Urochloa decumbens (Stapf) R.D.Webster, Urochloa humidicola (Rendle) Morrone \& Zuloaga) e nativas (CHEUNG, MARQUES e LIEBSCH, 2009).

Tabela 1. Características das parcelas florestais: idade, classe de solo, coordenadas geográficas (latitude e longitude) e altitude.

Table 1. Characteristics of forest plots: age, soil class, geographical coordinates (latitude and longitude) and elevation.

\begin{tabular}{ccccc}
\hline Idade (anos) & Classe de Solo* & Latitude S & Longitude W & Altitude (m) \\
\hline $\mathbf{2 5}$ & Cambissolo e Argissolo & $25^{\circ} 18^{\prime} 15,901^{\prime \prime}$ & $48^{\circ} 39^{\prime} 37,382^{\prime \prime}$ & 133 \\
\hline $\mathbf{( 4 5 - 7 0 ) ~ 6 0}$ & Cambissolo e Gleissolo & $25^{\circ} 19^{\prime} 15,773 "$ & $48^{\circ} 40^{\prime} 38,001^{\prime \prime}$ & 41 \\
\hline $\mathbf{( 7 5 - 8 0 )} \mathbf{7 5}$ & Cambissolo & $25^{\circ} 19^{\prime} 45,886^{\prime \prime}$ & $48^{\circ} 40^{\prime} 38,801^{\prime \prime}$ & 113 \\
\hline $\mathbf{9 0}$ & Cambissolo & $25^{\circ} 19^{\prime} 48,992^{\prime \prime}$ & $48^{\circ} 40^{\prime} 26,679^{\prime \prime}$ & 131 \\
\hline $\mathbf{1 0 0 A}^{*}$ & Cambissolo & $25^{\circ} 17^{\prime} 53,011^{\prime \prime}$ & $48^{\circ} 39^{\prime} 29,403^{\prime \prime}$ & 154 \\
\hline $\mathbf{1 0 0 B}$ & Cambissolo e Argissolo & $25^{\circ} 17^{\prime} 52,701^{\prime \prime}$ & $48^{\circ} 400^{\prime} 4,995^{\prime \prime}$ & 163 \\
\hline
\end{tabular}

*Fonte: Donha (2016); as letras A e B são usadas para diferenciar as duas parcelas com 100 anos de idade.

\section{Coleta de dados}

As árvores foram avaliadas em duas ocasiões (2007 e 2017), em parcelas permanentes com dimensões de $100 \mathrm{~m}$ x $100 \mathrm{~m}$. Todos os indivíduos arbóreos com diâmetro à altura do peito (DAP) maior ou igual $(\geq) 5 \mathrm{~cm}$ foram medidos, marcados e mapeados. Os dados de declividade foram obtidos entre os vértices de uma grade de $10 \mathrm{~m}$ x $10 \mathrm{~m}$, usando um clinômetro (Brunton®). A serapilheira acumulada foi quantificada após coletas usando um gabarito de $50 \mathrm{~cm}$ x $50 \mathrm{~cm}\left(0,25 \mathrm{~m}^{2}\right)$, em 25 pontos equidistantes (grade $20 \mathrm{~m}$ x $20 \mathrm{~m}$ ) dentro de cada floresta, em quatro ocasiões diferentes (inverno e verão de 2013; inverno e verão de 2014) (WOICIECHOWSKI, 2015). O material foi seco em estufa e pesado posteriormente. Amostras de solo também foram coletadas nos mesmos pontos onde se coletou a serapilheira, em três profundidades $(0$ a $5 \mathrm{~cm}, 5$ a $10 \mathrm{~cm}, 10$ a $20 \mathrm{~cm}$ ). Os atributos químicos do solo analisados nestas amostras foram: C orgânico, $\mathrm{pH}(\mathrm{CaCl} 2$ 0,01 mol/L); $\mathrm{P}$, $\mathrm{K}$ e $\mathrm{Na}$ (extrator Mehlich); $\mathrm{Ca}, \mathrm{Mg}$ e $\mathrm{Al}$ (extrator $\mathrm{KCl}$ ); $\mathrm{Cu}, \mathrm{Fe}, \mathrm{Mn}$ e $\mathrm{Zn}$ (extrator $\mathrm{HCl}$
$0,01 \mathrm{~mol} / \mathrm{L})$

\section{Análise e processamento}

Os valores de cada atributo químico do solo e da quantidade de serapilheira acumulada foram interpolados com uma função polinomial de Kernel, para uma distância de até 25 metros e, portanto, houve a ponderação dos valores (suavização) com as amostras vizinhas. Os valores de inclinação foram interpolados usando um modelo de elevação digital (MDE), gerado a partir da diferença de altitude entre os vértices. Os valores das interpolações para cada atributo químico de solo, para serapilheira acumulada e declividade foram extraídos para cada árvore, agregando-os como atributos na tabela de dados.

As parcelas foram divididas em subparcelas de $20 \mathrm{~m}$ x $20 \mathrm{~m}$. As variáveis estruturais (diâmetro máximo, área basal, altura máxima e número de árvores) foram calculadas em cada subparcela a partir dos dados coletados no primeiro levantamento (2007), assim passaram a ser consideradas preditoras das mudanças demográficas de uma década (2017). Padrões 
espaciais foram descritos por meio da função $\mathrm{K}$ de Ripley e da transformação da raiz quadrada, função $\mathrm{L}$, usando o desvio do valor teórico em distâncias consecutivas de um metro, até um máximo de 10 metros; ou seja, 10 padrões foram usados na ordenação. Os padrões espaciais foram analisados com o programa computacional "R" v. 3.3.2 (R, 2019) usando o pacote "spatstat" (BADDELEY, RUBAK e TURNER, 2015). As médias para os atributos químicos do solo, serapilheira acumulada e declividade foram obtidas para as subparcelas em função dos valores das árvores de cada subparcela.

As taxas de dinâmica foram estimadas a partir das equações programadas por Higuchi (2017). Para taxa de mortalidade, utilizou-se a proporção anual de árvores mortas em função do número de árvores no início e no final do intervalo de medição. A taxa de recrutamento foi quantificada pela proporção média anual de árvores que ingressaram. A taxa de rotatividade em número de árvores é a taxa média anual da mortalidade e do recrutamento. A taxa de perdas em área basal se refere à proporção de perda anual de área basal pelas árvores mortas e eventuais decrementos de sobreviventes. A taxa de ganho anual em área basal descreve a proporção de ganho de área basal com as recrutas e com o incremento em área basal das sobreviventes, e a taxa de rotatividade em área basal representa uma taxa anual média entre a taxa de perda e de ganhos de área basal.

As variáveis dependentes foram agrupadas em uma matriz e as variáveis explicativas em cinco matrizes multivariadas e duas univariadas (Tabela 2). A ordenação das matrizes com mais de uma variável foi realizada pela PCA e extraída apenas do eixo principal. Dados em proporção foram transformados pelo arco seno de raiz quadrada e posteriormente padronizados a escala com a divisão pelo desvio padrão. Os valores da estrutura e variáveis do solo foram transformados por logaritmo natural e padronizados com a divisão pelo desvio padrão. Uma árvore de inferência condicional (árvore de regressão) foi usada para predizer as taxas dinâmicas relacionadas à estrutura da floresta, aos atributos químicos do solo, ao padrão espacial, à declividade e à serapilheira acumulada (DE'ATH, 2002). O crescimento da árvore foi baseado em regras estatísticas de parada com função 'ctree.R' do pacote estatístico 'party' (HOTHORN, HORNIK e ZEILEIS, 2006), método pelo qual não foi necessário remover variáveis. Para a poda da árvore de regressão, a função testa a hipótese nula global de independência entre qualquer uma das variáveis de entrada com a resposta para o valor $\mathrm{p}$ menor que 0,05 . A qualidade da árvore de regressão foi avaliada por meio de boxplots e comparação das variáveis preditoras e variáveis respostas. Para isso, utilizou-se o teste de Kruskal-Wallis com comparações múltiplas $(p<0,05)$ e o critério da diferença menos significativa de Fisher. A estruturação espacial foi analisada visualmente pela distribuição das subparcelas dentro das florestas.

Padrões de composição de espécies de diferentes grupos foram comparados usando escalonamento multidimensional não-métrico (NMDS) e testados com análise de variância multivariada com permutação, usando matrizes de distância (PERMANOVA). O NMDS, usado para separar visualmente os grupos, foi aplicado com uma matriz de distância de dissimilaridade de Bray-Curtis com a função 'metaMDS', com 2 e 3 dimensões e 100 interações, enquanto a PERMANOVA foi aplicada usando 999 permutações com a função estatística 'adonis', ambas no pacote 'vegan' (OKSANEN et al., 2019) em R (R, 2019).

\section{Resultados}

As taxas de dinâmica demográfica (Mat."Y" na Tabela 2) sintetizadas pelo eixo principal da PCA (Figura 1A) explicaram uma proporção de $73 \%$ da inércia total. As variáveis que mais se correlacionaram com a ordenação foram a rotatividade em número de árvores (ROTAT.N, peso $=0,45)$ e a rotatividade em área basal $($ ROTAT.BA, peso $=0,45)$. 
Tabela 2. Valores médios e desvio padrão das variáveis resposta $(\mathrm{Y})$ e das possíveis variáveis explicativas em sete matrizes (X1, X2, X3, X4, X5, X6 e X7), em florestas secundárias com seis idades (25, 60, 75, 90, 100A e 100B) no sul do Brasil.

Table 2. Average values and standard deviation of the response variables $(\mathrm{Y})$ and the possible explanatory variables in seven matrices $(\mathrm{X} 1, \mathrm{X} 2, \mathrm{X} 3, \mathrm{X} 4, \mathrm{X} 5, \mathrm{X} 6$ and $\mathrm{X} 7)$ in secondary forests with six ages $(25,60,75,90,100 \mathrm{~A}$ and $100 \mathrm{~B})$ in southern Brazil.

\begin{tabular}{|c|c|c|c|c|c|c|c|}
\hline \multicolumn{2}{|c|}{ Variáveis } & \multicolumn{6}{|c|}{ Estande / idade } \\
\hline Mat. & Var. & 25 & 60 & 75 & 90 & $100 \mathrm{~A}$ & 100B \\
\hline \multirow{6}{*}{ Y } & TX.MORT & $2,69 \pm 1,12$ & $1,81 \pm 0,66$ & $1,53 \pm 0,66$ & $1,71 \pm 0,87$ & $1,51 \pm 0,49$ & $1,61 \pm 0,90$ \\
\hline & TX.RECR & $2,63 \pm 1,18$ & $0,98 \pm 0,71$ & $1,22 \pm 0,66$ & $1,71 \pm 0,75$ & $0,96 \pm 0,62$ & $0,70 \pm 0,37$ \\
\hline & ROTAT.N & $2,66 \pm 1,08$ & $1,39 \pm 0,56$ & $1,38 \pm 0,51$ & $1,72 \pm 0,69$ & $1,23 \pm 0,45$ & $1,16 \pm 0,44$ \\
\hline & TX.PE.AB & $2,95 \pm 1,78$ & $1,71 \pm 0,87$ & $1,59 \pm 1,26$ & $1,91 \pm 1,92$ & $1,42 \pm 0,97$ & $1,28 \pm 0,97$ \\
\hline & TX.GA.AB & $4,18 \pm 1,05$ & $2,25 \pm 0,68$ & $2,46 \pm 0,65$ & $2,95 \pm 0,84$ & $2,45 \pm 0,62$ & $1,80 \pm 0,42$ \\
\hline & ROTAT.AB & $3,57 \pm 1,20$ & $1,98 \pm 0,64$ & $2,02 \pm 0,80$ & $2,43 \pm 1,17$ & $1,93 \pm 0,62$ & $1,54 \pm 0,55$ \\
\hline \multirow{12}{*}{$\mathrm{X} 1$} & $\mathrm{C}$ & $39,42 \pm 6,65$ & $44,93 \pm 7,62$ & $43,14 \pm 7,02$ & $36,51 \pm 6,26$ & $23,97 \pm 7,43$ & $33,50 \pm 5,71$ \\
\hline & $\mathrm{pH}$ & $3,42 \pm 0,10$ & $3,20 \pm 0,18$ & $2,82 \pm 0,24$ & $3,59 \pm 0,28$ & $3,57 \pm 0,14$ & $3,52 \pm 0,10$ \\
\hline & $\mathrm{P}$ & $10,70 \pm 6,37$ & $5,18 \pm 1,69$ & $5,43 \pm 1,23$ & $7,41 \pm 4,27$ & $8,57 \pm 1,69$ & $4,18 \pm 0,74$ \\
\hline & $\mathrm{Ca}$ & $0,50 \pm 0,15$ & $0,15 \pm 0,10$ & $0,41 \pm 0,07$ & $0,99 \pm 0,69$ & $1,06 \pm 0,47$ & $0,45 \pm 0,20$ \\
\hline & $\mathrm{K}$ & $0,15 \pm 0,02$ & $0,11 \pm 0,02$ & $0,12 \pm 0,02$ & $0,16 \pm 0,02$ & $0,21 \pm 0,04$ & $0,13 \pm 0,02$ \\
\hline & $\mathrm{Mg}$ & $0,59 \pm 0,24$ & $0,29 \pm 0,12$ & $0,43 \pm 0,11$ & $0,89 \pm 0,31$ & $0,59 \pm 0,19$ & $0,52 \pm 0,19$ \\
\hline & $\mathrm{Al}$ & $1,95 \pm 0,20$ & $2,94 \pm 0,23$ & $2,38 \pm 0,38$ & $1,58 \pm 0,51$ & $1,68 \pm 0,34$ & $2,00 \pm 0,21$ \\
\hline & $\mathrm{Na}$ & $0,06 \pm 0,02$ & $0,06 \pm 0,02$ & $0,07 \pm 0,01$ & $0,06 \pm 0,01$ & $0,08 \pm 0,01$ & $0,08 \pm 0,02$ \\
\hline & $\mathrm{Cu}$ & $0,08 \pm 0,04$ & $0,02 \pm 0,02$ & $0,04 \pm 0,01$ & $0,08 \pm 0,03$ & $0,08 \pm 0,03$ & $0,09 \pm 0,02$ \\
\hline & $\mathrm{Fe}$ & $15,73 \pm 1,32$ & $10,56 \pm 3,13$ & $10,68 \pm 2,35$ & $11,97 \pm 2,92$ & $7,93 \pm 1,38$ & $8,69 \pm 1,78$ \\
\hline & $\mathrm{Mn}$ & $1,23 \pm 0,40$ & $0,14 \pm 0,05$ & $0,96 \pm 1,07$ & $3,38 \pm 2,02$ & $3,96 \pm 1,51$ & $2,90 \pm 1,53$ \\
\hline & $\mathrm{Zn}$ & $0,22 \pm 0,13$ & $0,14 \pm 0,10$ & $0,18 \pm 0,08$ & $0,23 \pm 0,08$ & $0,27 \pm 0,08$ & $0,24 \pm 0,07$ \\
\hline \multirow{12}{*}{$\mathrm{X} 2$} & $\mathrm{C}$ & $25,64 \pm 4,47$ & $34,88 \pm 3,57$ & $31,48 \pm 3,10$ & $29,89 \pm 4,16$ & $20,08 \pm 5,03$ & $25,56 \pm 5,84$ \\
\hline & $\mathrm{pH}$ & $3,44 \pm 0,10$ & $3,30 \pm 0,16$ & $2,91 \pm 0,17$ & $3,54 \pm 0,22$ & $3,57 \pm 0,11$ & $3,55 \pm 0,06$ \\
\hline & $\mathrm{P}$ & $9,24 \pm 6,48$ & $5,36 \pm 2,68$ & $3,91 \pm 0,66$ & $9,22 \pm 12,79$ & $8,10 \pm 3,13$ & $3,19 \pm 0,92$ \\
\hline & $\mathrm{Ca}$ & $0,26 \pm 0,10$ & $0,15 \pm 0,10$ & $0,32 \pm 0,05$ & $0,55 \pm 0,49$ & $0,68 \pm 0,42$ & $0,13 \pm 0,06$ \\
\hline & $\mathrm{K}$ & $0,10 \pm 0,01$ & $0,09 \pm 0,02$ & $0,09 \pm 0,02$ & $0,13 \pm 0,02$ & $0,15 \pm 0,03$ & $0,09 \pm 0,01$ \\
\hline & $\mathrm{Mg}$ & $0,25 \pm 0,11$ & $0,20 \pm 0,09$ & $0,26 \pm 0,07$ & $0,61 \pm 0,21$ & $0,40 \pm 0,18$ & $0,24 \pm 0,09$ \\
\hline & $\mathrm{Al}$ & $2,02 \pm 0,21$ & $2,90 \pm 0,36$ & $2,36 \pm 0,31$ & $2,00 \pm 0,47$ & $1,97 \pm 0,34$ & $2,43 \pm 0,31$ \\
\hline & $\mathrm{Na}$ & $0,04 \pm 0,01$ & $0,06 \pm 0,01$ & $0,05 \pm 0,01$ & $0,05 \pm 0,01$ & $0,06 \pm 0,01$ & $0,06 \pm 0,01$ \\
\hline & $\mathrm{Cu}$ & $15,60 \pm 1,23$ & $11,07 \pm 2,92$ & $9,97 \pm 2,29$ & $12,76 \pm 3,22$ & $8,45 \pm 1,48$ & $10,41 \pm 1,75$ \\
\hline & $\mathrm{Fe}$ & $0,06 \pm 0,04$ & $0,02 \pm 0,01$ & $0,04 \pm 0,01$ & $0,07 \pm 0,03$ & $0,08 \pm 0,03$ & $0,07 \pm 0,02$ \\
\hline & Mn & $0,43 \pm 0,17$ & $0,10 \pm 0,04$ & $0,57 \pm 0,64$ & $2,16 \pm 1,32$ & $2,87 \pm 1,20$ & $0,94 \pm 0,42$ \\
\hline & $\mathrm{Zn}$ & $0,13 \pm 0,09$ & $0,13 \pm 0,08$ & $0,16 \pm 0,07$ & $0,17 \pm 0,06$ & $0,22 \pm 0,10$ & $0,14 \pm 0,04$ \\
\hline \multirow{12}{*}{$\mathrm{X} 3$} & $\mathrm{C}$ & $20,73 \pm 4,28$ & $27,83 \pm 4,09$ & $21,65 \pm 2,90$ & $26,90 \pm 7,95$ & $16,07 \pm 4,22$ & $17,67 \pm 4,41$ \\
\hline & $\mathrm{pH}$ & $3,49 \pm 0,11$ & $3,36 \pm 0,11$ & $3,03 \pm 0,13$ & $3,50 \pm 0,12$ & $3,64 \pm 0,11$ & $3,65 \pm 0,08$ \\
\hline & $\mathrm{P}$ & $7,67 \pm 5,08$ & $3,79 \pm 1,18$ & $3,01 \pm 2,11$ & $3,87 \pm 2,16$ & $5,97 \pm 1,62$ & $1,96 \pm 0,82$ \\
\hline & $\mathrm{Ca}$ & $0,21 \pm 0,08$ & $0,13 \pm 0,09$ & $0,27 \pm 0,03$ & $0,26 \pm 0,23$ & $0,32 \pm 0,38$ & $0,08 \pm 0,07$ \\
\hline & $\mathrm{K}$ & $0,07 \pm 0,01$ & $0,08 \pm 0,01$ & $0,05 \pm 0,01$ & $0,11 \pm 0,03$ & $0,11 \pm 0,02$ & $0,06 \pm 0,01$ \\
\hline & $\mathrm{Mg}$ & $0,12 \pm 0,05$ & $0,13 \pm 0,05$ & $0,15 \pm 0,04$ & $0,38 \pm 0,16$ & $0,23 \pm 0,17$ & $0,14 \pm 0,10$ \\
\hline & $\mathrm{Al}$ & $1,99 \pm 0,16$ & $2,84 \pm 0,31$ & $2,01 \pm 0,20$ & $2,15 \pm 0,33$ & $3,64 \pm 5,40$ & $2,11 \pm 0,31$ \\
\hline & $\mathrm{Na}$ & $0,03 \pm 0,01$ & $0,04 \pm 0,01$ & $0,03 \pm 0,01$ & $0,04 \pm 0,01$ & $0,04 \pm 0,01$ & $0,04 \pm 0,01$ \\
\hline & $\mathrm{Cu}$ & $13,36 \pm 2,12$ & $12,81 \pm 2,93$ & $11,76 \pm 2,42$ & $12,93 \pm 3,00$ & $9,18 \pm 1,96$ & $11,04 \pm 1,90$ \\
\hline & $\mathrm{Fe}$ & $0,05 \pm 0,03$ & $0,02 \pm 0,01$ & $0,03 \pm 0,01$ & $0,08 \pm 0,03$ & $0,08 \pm 0,03$ & $0,06 \pm 0,02$ \\
\hline & $\mathrm{Mn}$ & $0,23 \pm 0,11$ & $0,09 \pm 0,02$ & $0,72 \pm 0,99$ & $1,67 \pm 1,29$ & $1,79 \pm 0,93$ & $0,55 \pm 0,30$ \\
\hline & $\mathrm{Zn}$ & $0,10 \pm 0,11$ & $0,11 \pm 0,09$ & $0,12 \pm 0,08$ & $0,14 \pm 0,06$ & $0,15 \pm 0,06$ & $0,09 \pm 0,03$ \\
\hline
\end{tabular}

continua 
continuação

Tabela 2. Valores médios e desvio padrão das variáveis resposta (Y) e das possíveis variáveis explicativas em sete matrizes (X1, X2, X3, X4, X5, X6 e X7), em florestas secundárias com seis idades (25, 60, 75, 90, 100A e 100B) no sul do Brasil.

Table 2. Average values and standard deviation of the response variables $(\mathrm{Y})$ and the possible explanatory variables in seven matrices $(X 1, X 2, X 3, X 4, X 5, X 6$ and X7) in secondary forests with six ages $(25,60,75,90,100 \mathrm{~A}$ and 100B) in southern Brazil.

\begin{tabular}{cccccccc}
\hline \multicolumn{6}{c}{ Variáveis } & \multicolumn{7}{c}{ Estande / idade } \\
\hline Mat. & Var. & $\mathbf{2 5}$ & $\mathbf{6 0}$ & $\mathbf{7 5}$ & $\mathbf{9 0}$ & $\mathbf{1 0 0 A}$ & $\mathbf{1 0 0 B}$ \\
\hline & N (ind ha $\left.{ }^{-1}\right)$ & $2132 \pm 315$ & $1722 \pm 357$ & $1927 \pm 298$ & $1604 \pm 270$ & $1624 \pm 333$ & $1619 \pm 182$ \\
& DAP_máx & $1,56 \pm 11,30$ & $40,30 \pm 8,99$ & $49,47 \pm 9,97$ & $57,86 \pm 18,72$ & $51,15 \pm 11,38$ & $45,10 \pm 9,30$ \\
X4 & (cm) & & & & \\
& Alt_máx (m) & $14,16 \pm 1,93$ & $19,74 \pm 2,14$ & $20,96 \pm 2,35$ & $18,96 \pm 3,77$ & $18,36 \pm 2,72$ & $17,92 \pm 2,43$ \\
& AB (m² ha $\left.{ }^{-1}\right)$ & $22,70 \pm 4,81$ & $31,02 \pm 8,08$ & $33,28 \pm 6,77$ & $32,23 \pm 8,08$ & $32,35 \pm 6,85$ & $32,87 \pm 6,11$ \\
\hline & L1 & $0,28 \pm 0,14$ & $0,07 \pm 0,14$ & $0,09 \pm 0,16$ & $0,10 \pm 0,13$ & $0,01 \pm 0,15$ & $0,08 \pm 0,12$ \\
& L2 & $0,18 \pm 0,16$ & $0,03 \pm 0,13$ & $0,03 \pm 0,13$ & $0,06 \pm 0,16$ & $-0,02 \pm 0,14$ & $0,08 \pm 0,10$ \\
& L3 & $0,10 \pm 0,16$ & $0,03 \pm 0,13$ & $-0,03 \pm 0,10$ & $0,05 \pm 0,23$ & $-0,05 \pm 0,15$ & $0,03 \pm 0,14$ \\
& L4 & $0,09 \pm 0,17$ & $-0,01 \pm 0,16$ & $-0,04 \pm 0,12$ & $0,03 \pm 0,31$ & $-0,04 \pm 0,10$ & $0,01 \pm 0,13$ \\
X5 & L5 & $0,07 \pm 0,17$ & $-0,03 \pm 0,13$ & $-0,04 \pm 0,11$ & $0,06 \pm 0,30$ & $-0,02 \pm 0,13$ & $-0,01 \pm 0,12$ \\
& L6 & $0,10 \pm 0,21$ & $-0,05 \pm 0,15$ & $-0,02 \pm 0,11$ & $0,06 \pm 0,29$ & $-0,01 \pm 0,12$ & $-0,02 \pm 0,13$ \\
& L7 & $0,08 \pm 0,21$ & $-0,06 \pm 0,16$ & $-0,02 \pm 0,12$ & $0,02 \pm 0,31$ & $-0,01 \pm 0,15$ & $0,01 \pm 0,16$ \\
& L8 & $0,04 \pm 0,24$ & $-0,03 \pm 0,16$ & $-0,01 \pm 0,15$ & $0,02 \pm 0,30$ & $-0,01 \pm 0,19$ & $0,00 \pm 0,17$ \\
& L9 & $0,01 \pm 0,28$ & $-0,04 \pm 0,20$ & $0,02 \pm 0,19$ & $0,03 \pm 0,30$ & $-0,02 \pm 0,19$ & $0,00 \pm 0,23$ \\
& L10 & $0,01 \pm 0,28$ & $-0,04 \pm 0,21$ & $0,05 \pm 0,20$ & $0,06 \pm 0,31$ & $0,00 \pm 0,22$ & $0,01 \pm 0,24$ \\
\hline X6 & Declividade & $17,54 \pm 3,89$ & $12,82 \pm 6,02$ & $17,82 \pm 6,06$ & $11,91 \pm 4,95$ & $13,9 \pm 3,85$ & $18,43 \pm 4,21$ \\
\hline X7 & Serapilheira & $2,81 \pm 0,41$ & $3,05 \pm 0,53$ & $3,09 \pm 0,52$ & $3,26 \pm 0,63$ & $3,47 \pm 0,47$ & $4,43 \pm 0,43$ \\
\hline
\end{tabular}

Onde: Y1) Mudança temporal por taxa de mortalidade (TX.MORT), taxa de recrutamento (TX.RECR), taxa de rotatividade em número de árvores (ROTAT.N), taxa de perda em área basal (TX.PE.AB), taxa de ganho de área basal (TX.GA.AB) e taxa de rotatividade em área basal (ROTAT.AB); X1) Estrutura florestal no ano de 2007; Atributos químicos do solo na profundidade de 0 a $5 \mathrm{~cm}$; X2) Atributos químicos do solo na profundidade de 05 a $510 \mathrm{~cm}$; X3) Atributos químicos do solo na profundidade de 5 a $10 \mathrm{~cm}$; X4) Atributos químicos do solo na profundidade de 10 a $20 \mathrm{~cm}$; X4) Estrutura florestal no ano de 2007; X5) Padrão espacial (Função K de Ripley) no ano de 2007 em diferentes escalas (1 a 10 m); X6) Declividade em graus; X7) Quantidade de serapilheira acumulada.

O ordenamento dos atributos químicos (Figura 1B) da superfície do solo (0 a $5 \mathrm{~cm}$ ) (Mat."X1" na Tabela 2) explicaram 43\% da inércia total pelo eixo principal, com as variáveis mais correlacionadas $\mathrm{Ca}$ e $\mathrm{Mn}$ (peso = -0,38). Na profundidade de 5 a $10 \mathrm{~cm}$ (Mat.”X2" na Tabela 2), a ordenação dos atributos químicos (Figura 1C) explicou 39\% da inércia total pelo eixo principal, com as variáveis mais correlacionadas $\mathrm{Mn}$ e $\mathrm{Ca}$ (peso = $-0,40$ e $-0,38$, respectivamente). $\mathrm{Na}$ profundidade de 10 a $20 \mathrm{~cm}$ (Mat."X3" na Tabela 2), a ordenação dos atributos químicos (Figura 1D) explicou $30 \%$ da inércia total pelo eixo principal, com as variáveis mais correlacionadas $\mathrm{Mg}$ e $\mathrm{K}$ (peso = 0,43).

Para a estrutura da floresta (Mat.X4 na Tabela 2), a proporção de variação explicada pelo eixo principal (Figura 1E) foi de $54 \%$ da inércia total, com a sequência de variáveis com maior peso dada pelo diâmetro máximo (DAP_máx, peso $=-0,60)$, área basal $(\mathrm{AB}$, peso $=-0,57)$ e altura máxima (Alt_máx, peso=$0,532)$.

A ordenação dos padrões espaciais (Mat."X5" na Tabela 2) explicou uma proporção de $53 \%$ da inércia total no eixo principal (Figura 1F). Os padrões espaciais mais correlacionados com o eixo principal foram distâncias de 6 e 7 metros (peso $=0,38$ ). 

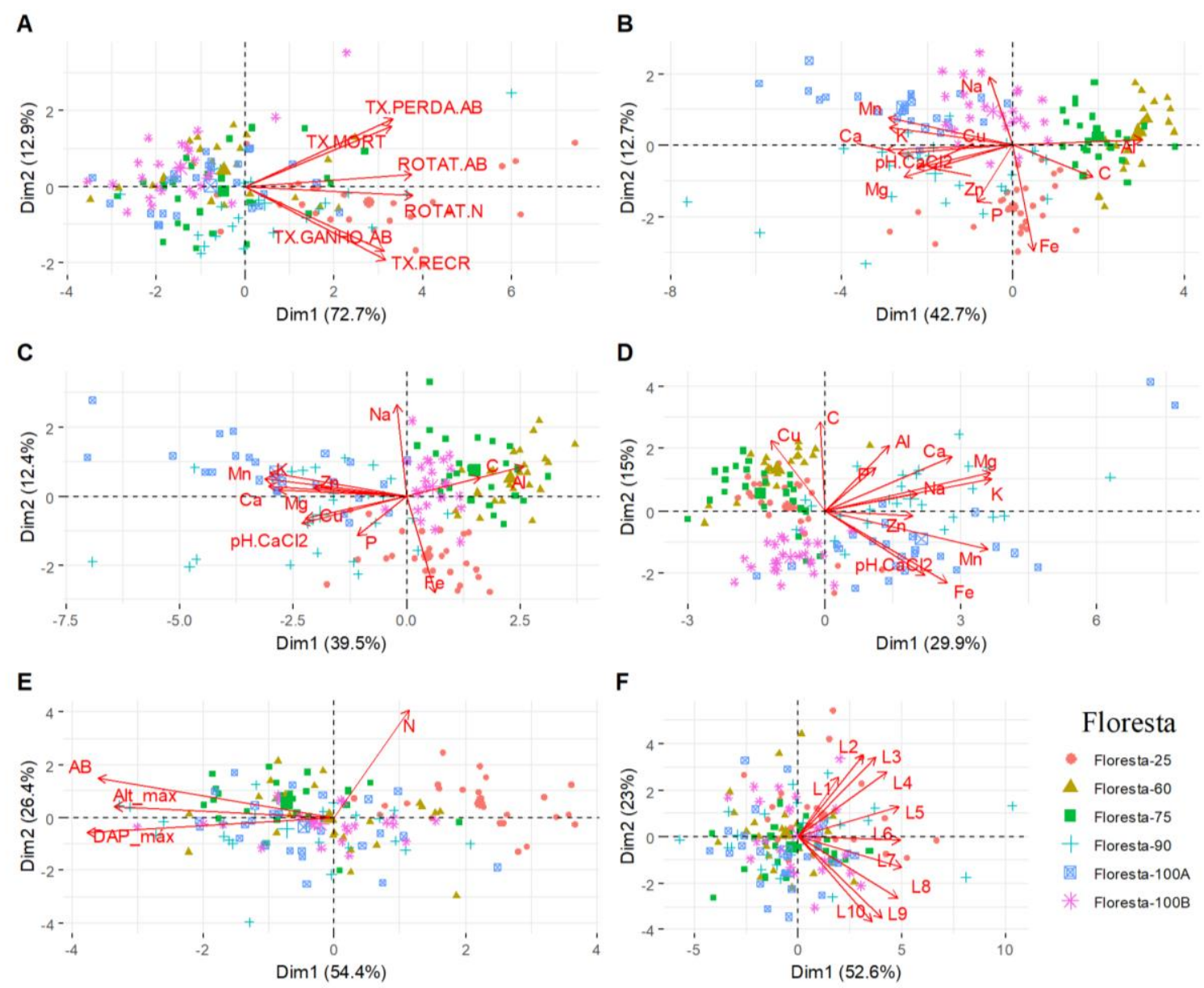

Figura 1. Gráficos de ordenação de Análise de Componentes Principais (PCA) para florestas com seis idades (Grupos) pósperturbação (Floresta-25, Floresta-60, Floresta-75, Floresta-90, Floresta-100A e Floresta-100B). A: taxas de dinâmica; B: Atributos químicos do solo na profundidade de 0 a $5 \mathrm{~cm}$; C: atributos químicos do solo na profundidade de 5 a $10 \mathrm{~cm}$; D: atributos químicos do solo na profundidade de 10 a $20 \mathrm{~cm}$ de profundidade; E: parâmetros estruturais; F: padrões espaciais.

Figure 1. Ordination graphics of Principal Component Analysis (PCA) for forests with six ages post-disturbance (Floresta25, Floresta-60, Floresta-75, Floresta-90, Floresta-100A and Floresta-100B). A: Dynamics rates; B: Chemical attributes of soil in the depth of 0 to $5 \mathrm{~cm}$; C: Soil chemical attributes in the depth of 5 to $10 \mathrm{~cm}$; D: Soil chemical attributes in the depth of 10 to $20 \mathrm{~cm}$ depth; E: Structural parameters; F: Spatial patterns.

A árvore de regressão revelou três subgrupos finais (Figura 2) associados com a estrutura da floresta (Nó 1) e com a quantidade de serapilheira acumulada (Nó 2).

As áreas com estrutura menos desenvolvida apresentaram valores maiores de 1,908 no eixo principal da PCA; isto é, foram as áreas com altura máxima menor, diâmetro máximo menor e menor área basal. Essas áreas estiveram associadas com valores mais altos das taxas de dinâmica (Nó 5). Áreas com estrutura arbórea mais desenvolvida, ou seja, com árvores médias e grandes e maior área basal $(\leq 1,908$ no eixo principal da PCA, Figura 1E), e com menor quantidade de serapilheira acumulada $(\leq 3,264$ $\mathrm{Mg} \mathrm{ha}{ }^{-1}$ ), estiveram associadas aos valores intermediários das taxas de dinâmica (Nó 3). Áreas com estrutura arbórea mais desenvolvida $(\leq 1,908)$ e com maior quantidade de serapilheira acumulada (> 3,264 $\mathrm{Mg} \mathrm{ha}{ }^{-1}$ ) estiveram associadas com menores taxas de dinâmica (Nó 4). Ou seja, a quantidade de serapilheira acumulada, a altura máxima, o diâmetro máximo e a área basal foram inversamente associados com as taxas de dinâmica demográficas. 


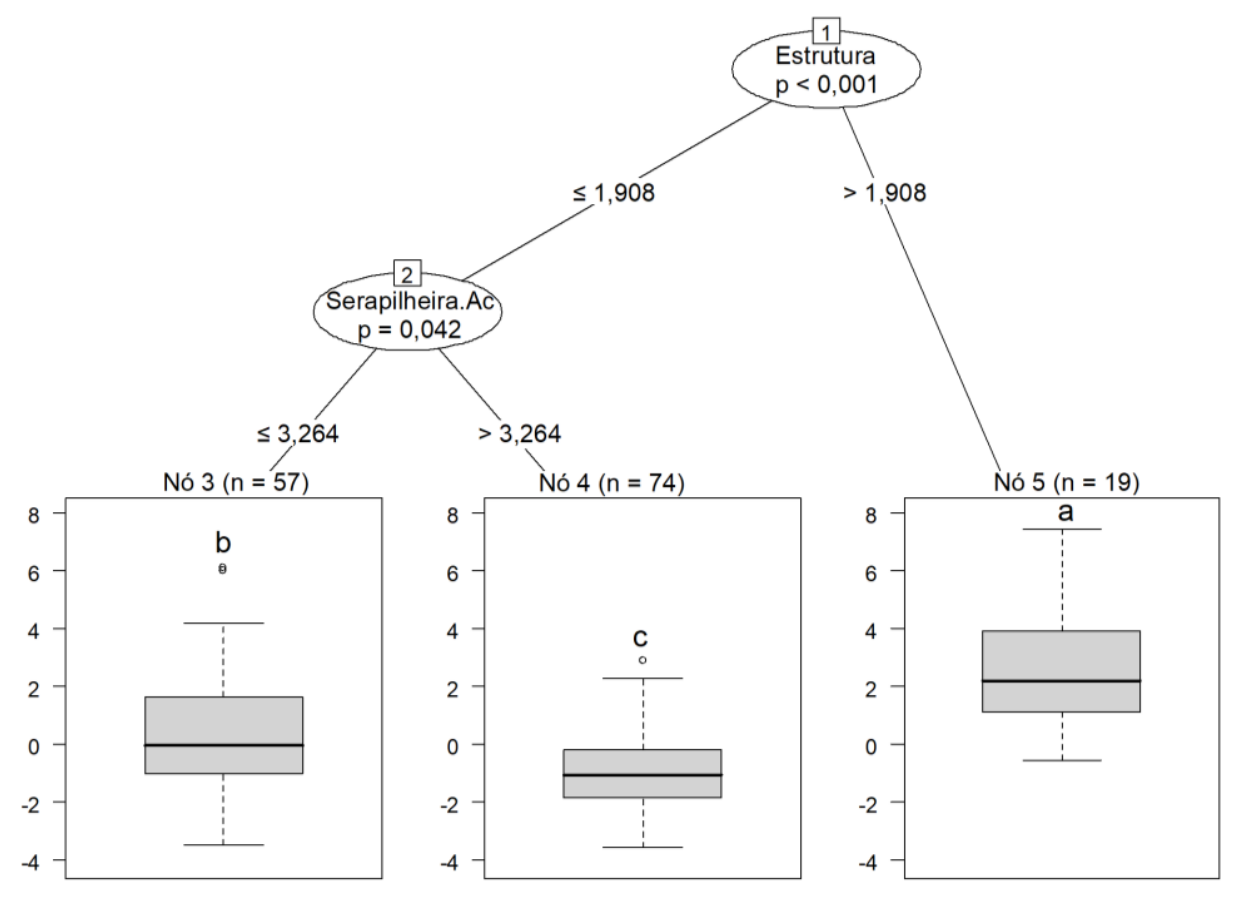

Figura 2. Árvore de regressão do eixo principal de ordenação das taxas demográficas (boxplots) em função da quantidade de serapilheira acumulada (Serapilheira.Ac) e do eixo principal da ordenação da estrutura florestal (Estrutura). Nós finais (Nó 3; Nó 4 e Nó 5) indicam o número de observações (n). Boxplots representam as medianas e quartis com os limites inferior e superior dos valores da ordenação das taxas de dinâmica em cada grupo. Letras diferentes nos boxplots indicam diferença significativa $(\mathrm{p}<0,05)$ de acordo com o teste de Kruskal-Wallis.

Figure 2. Regression tree of the main axis of demographic rates ordination (boxplots) as a function of the amount of litter (Serapilheira.Ac), and of the main axis of the forest structure ordination (Estutura). End nodes (Node 3, Node 4 and Node 5) indicate the number of observations (n). Boxplots represent the medians and quartiles with the lower and upper limits of the dynamics ordering values in each group. Different letters in the boxplots indicate significant difference $(\mathrm{p}<0.05)$ according the Kruskal-Wallis test.

As correlações e distribuição das variáveis (Figura 3) revelaram associação significativa entre as variáveis preditas e preditoras. As variáveis individuais da estrutura formaram padrões mais estocásticos, apresentando maior nulidade nas correlações, principalmente a abundância e a altura máxima. Já o componente principal da estrutura (Cp1.ESTRUT) foi altamente correlacionado com todas as outras variáveis, sugerindo que a utilização conjunta de variáveis estruturais é mais eficiente para a predição da dinâmica.

A espacialização dos grupos (Figura 4), formados pelos nós finais da árvore de regressão, evidenciou autocorrelação espacial com maior estocasticidade na floresta mais jovem (Figura 4A). As florestas avaliadas apresentaram altitude entre 26 e 180 metros aproximadamente; com desnível variando até 40 metros entre as extremidades de uma parcela, embora não tenha sido observada relação das taxas de dinâmica com a declividade (Figura 4).

A comparação dos subgrupos em relação às variáveis preditas e preditoras (Figura 5) demonstrou que o resultado foi explicado de forma satisfatória. As principais variáveis preditas (rotatividade em abundância (ROTAT.N) e em área basal (ROTAT.AB)) foram significativamente diferentes $(\mathrm{p}<0,05)$ entre os grupos formados pela árvore de regressão. As variáveis da estrutura arbórea 
(diâmetro máximo, altura máxima e área basal) foram significativamente diferentes $(\mathrm{p}<0,05)$ entre os grupos separados pelo Nó 1 da árvore de regressão. A serapilheira acumulada também foi significativamente diferente $(\mathrm{p}<0,05)$ entre os grupos separados pelo Nó 2 da árvore de regressão.

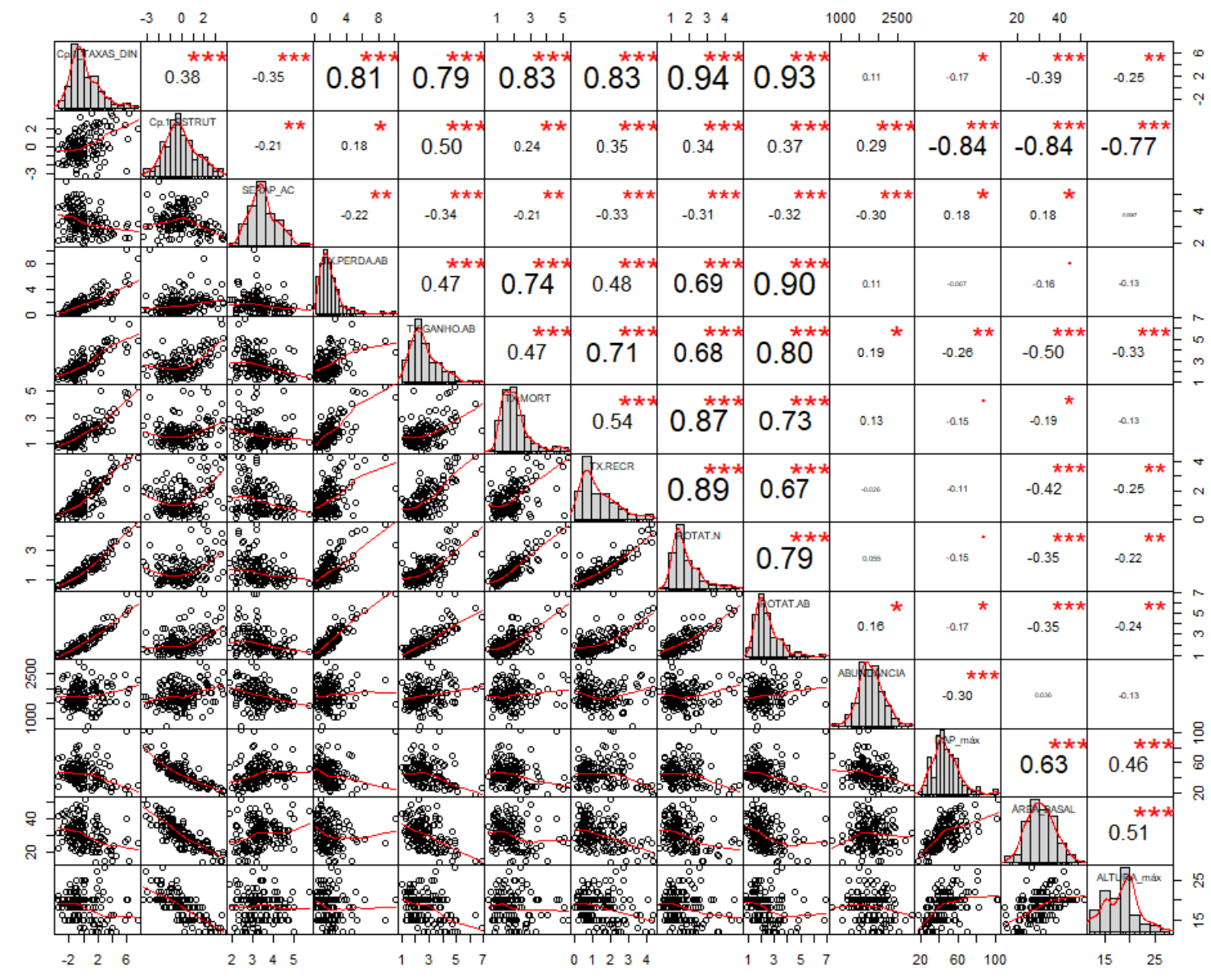

Figura 3. Análise exploratória das taxas de dinâmica da comunidade arbórea (cp.1_TAXAS_DIN: principal componente da PCA das taxas de dinâmica; cp.1_ESTRUT: principal componente da PCA da estrutura arbórea; SERAP_AC: serapilheira acumulada; TX.PERDA.AB: perda em área basal; TX.GANHO.AB: ganho de área basal; TX.MORT: mortalidade; TX.RECR: recrutamento; ROTAT.N: rotatividade em abundância; ROTAT.AB: rotatividade em área basal) e das variáveis explicativas (ABUNDÂNCIA: abundância; DAP_máx: diâmetro máximo; AB: área basal; Alt_máx: altura máxima) em seis florestas com idade distinta $(25,60,75,90,100 \mathrm{~A}$ e 100B). A diagonal representa histogramas que indicam a distribuição das parcelas em classes de valores das taxas de dinâmica e das variáveis explicativas. A diagonal superior representa a correlação e a significância das relações entre as taxas e variáveis $(* * *=0,001 ; * *=0,01 ; *=0,05)$. A diagonal inferior representa gráficos de dispersão da relação entre as taxas e variáveis.

Figure 3. Exploratory analysis of the tree community dynamics rates (cp.1_TAXAS_DIN: main component of PCA for dynamics rates; cp.1_ESTRUT: main component of PCA for tree structure; SERAP_AC: litter; TX.PERDA.AB: loss in basal area ; TX.GANHO.AB: basal area gain; TX.MORT: mortality; TX.RECR: recruitment; ROTAT.N: turnover in abundance; ROTAT.AB: turnover in basal area), and the explanatory variables (ABUNDÂNCIA: abundance, DAP_max: maximum diameter, AB: basal area, Alt_max: maximum height) in six forest stands with different age $(25,60,75,90,100 \mathrm{~A}$ and 100B). The diagonal represents histograms which indicate the distribution of the plots by classes of dynamics rates values against the explanatory variables. The upper diagonal represents the correlation and the significance of the relations between the rates and variables $(* * *=0.001 ; * *=0.01 ; *=0.05)$. The lower diagonal represents scatter plots of the relationship between rates and variables. 


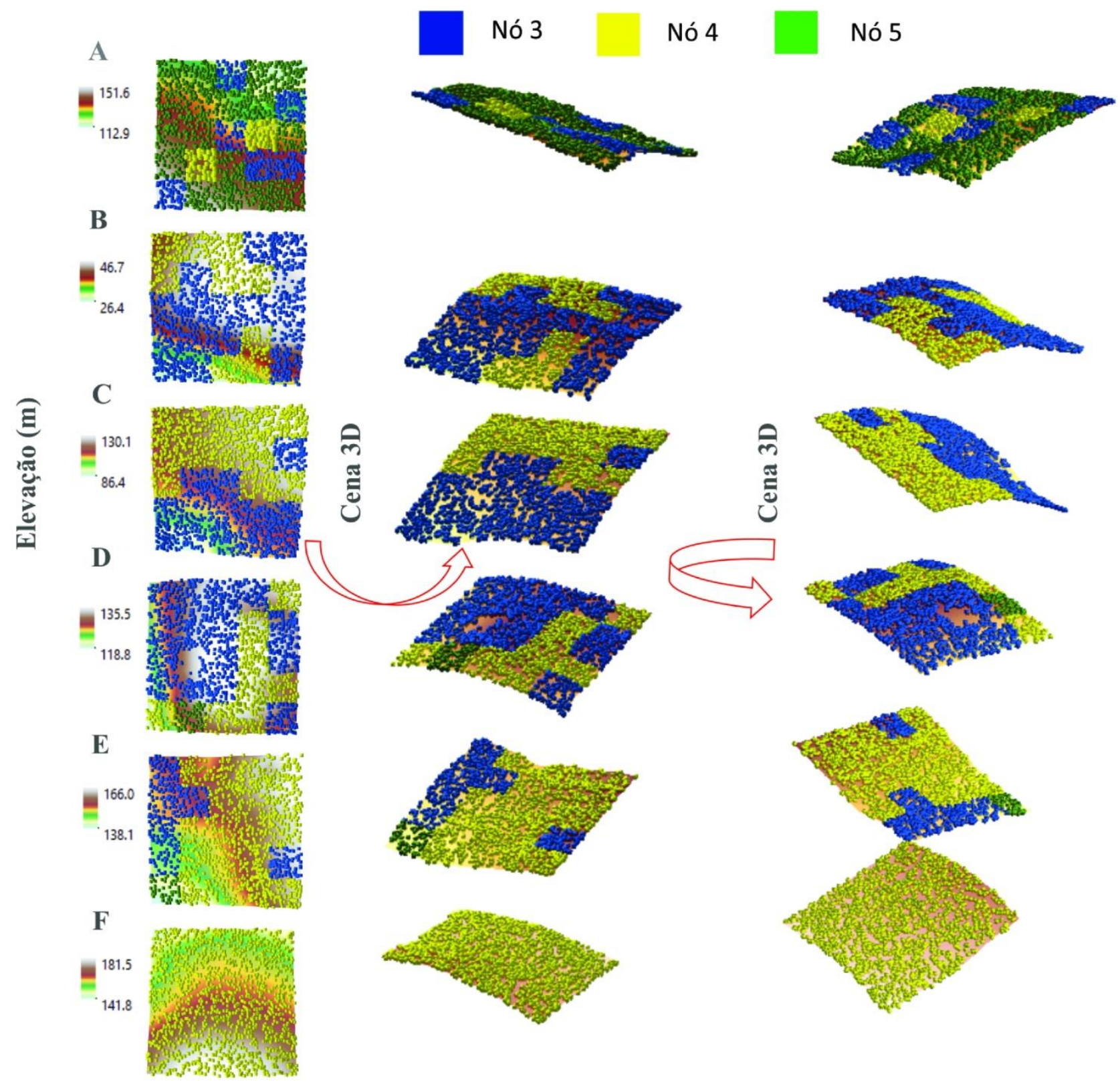

Figura 4. Grupos formados pela árvore de regressão (nós finais: Nó $3=$ azul; Nó 4 = amarelo; Nó 5 = verde) em florestas com seis idades pós-perturbação (A: 25, B: 60, C: 75, D: 90, E: 100A e F: 100B) destacando-se as diferenças de declive.

Figure 4. Groups formed by the regression tree (end nodes: Node $3=$ blue; Node $4=$ yellow; Node $5=$ green) in forests with six post-disturbance ages (A: 25, B: 60, C: 75, D: 90, E: 100A and F: 100B) highlighting the declivity differences. 

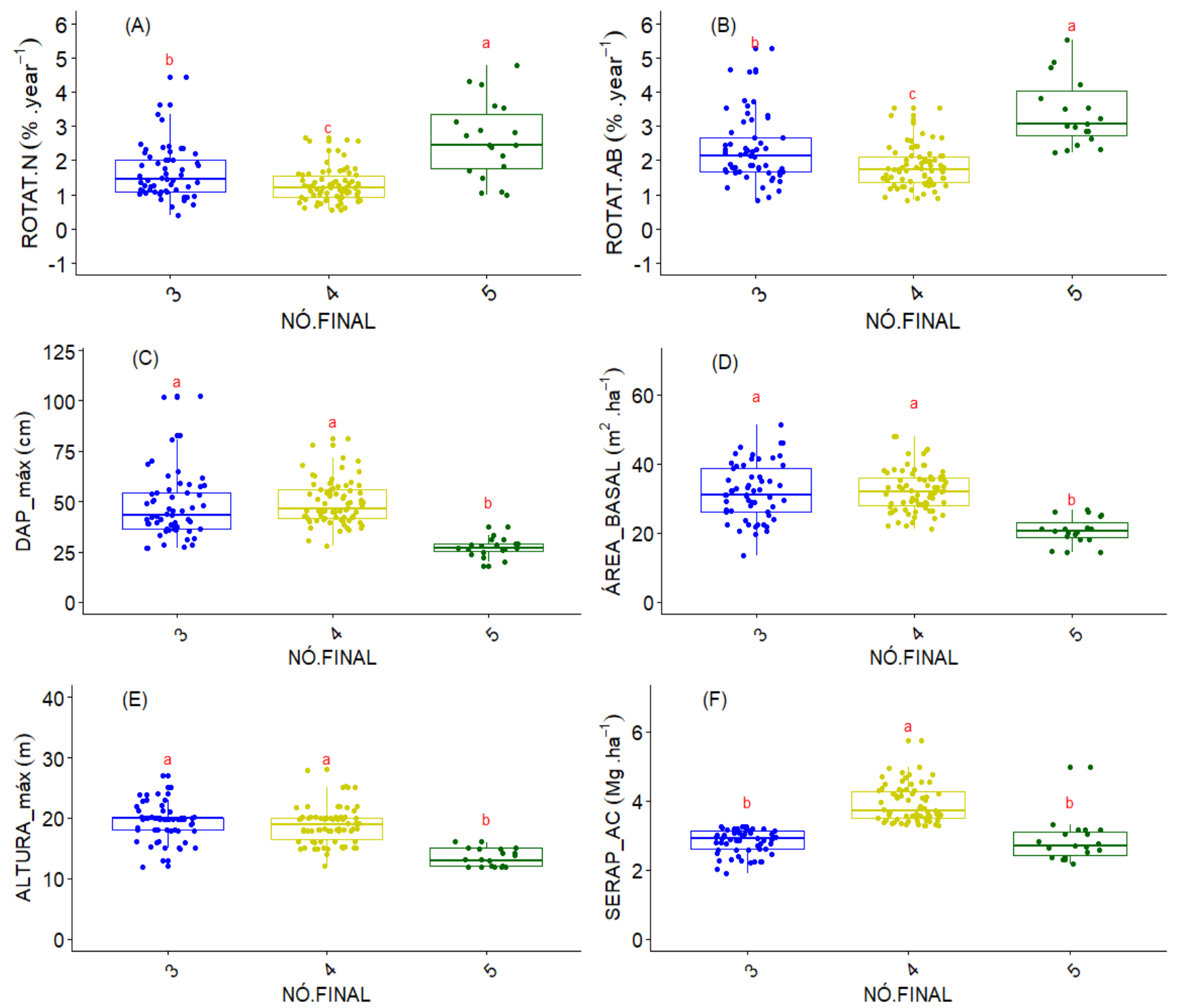

Figura 5. Comparação entre os nós finais formados pela árvore de regressão quanto às variações observadas para: taxa de rotatividade em abundância (A), taxa de rotatividade em área basal (B) DAP máximo (C), Área Basal (D), Altura máxima (E) e serapilheira acumulada (F). Boxplots representam as medianas e quartis com os limites inferior e superior. Letras diferentes nos boxplots indicam diferença significativa $(\mathrm{p}<0,05)$ de acordo com o teste de Kruskal-Wallis.

Figure 5. Comparison between the final nodes formed by the regression tree regarding the variations observed for: abundance turnover rate (A), turnover rate in basal area (B) maximum DAP (C), Basal area (D), maximum height ) and litter (F). Boxplots represent the medians and quartiles with the lower and upper limits. Different letters in the boxplots indicate significant difference ( $\mathrm{p}<0.05$ ) according to the Kruskal-Wallis test.

A ordenação NMDS com duas dimensões sobrepôs parcialmente os grupos (Figura 6), sendo o Nó 5 mais dissimilar do que os outros dois: Nó 3 e Nó 4. Ao considerar três dimensões na NMDS, o valor de stress reduziu de 0,17 para 0,13 , sugerindo diferenciação na composição das espécies. Os padrões de composição do Nó 3 e do Nó 4 foram menos dissimilares, mas com diferença significativa entre eles, de acordo com a PERMANOVA ( $p$ $<0,001)$. 


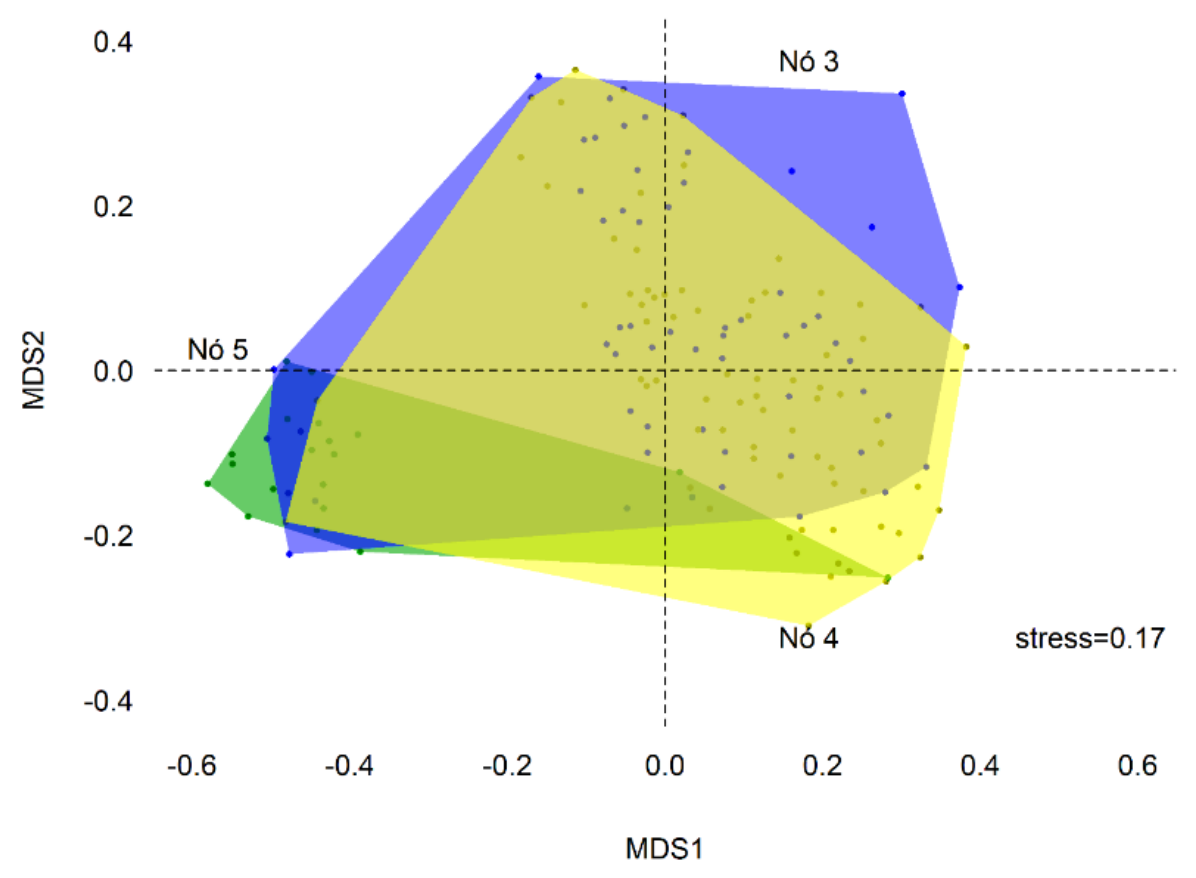

Figura 6. Escalonamento Multidimensional Não-Métrico (NMDS) das espécies que ocorrem nos nós terminais formados pela árvore de regressão. Nó $3=$ azul; Nó $4=$ amarelo; Nó $5=$ verde.

Figure 6. Non-Metric Multidimensional Scheduling (NMDS) of the species occurring at terminal nodes formed by the regression tree. Node $3=$ blue; Node 4 = yellow; Node 5 = green.

\section{Discussão}

As mudanças demográficas que mais variaram localmente foram a rotatividade em abundância e a rotatividade em área basal, que representam uma média das taxas de perda (mortalidade e decrescimento) e de ganhos (recrutamento e crescimento); e são interpretadas como uma medida de velocidade das mudanças (SALAMI et al., 2014). Com isso, as taxas de dinâmica consideradas neste estudo foram positivamente relacionadas (Figura 1A, Figura 3) e preditas em função de parâmetros estruturais (principalmente $\mathrm{o}$ diâmetro máximo, altura máxima e área basal) e da quantidade de serapilheira acumulada (Figura 2).

Áreas com árvores de menor porte e menor área basal ocorreram, principalmente, na idade pós-perturbação mais recente, onde a substituição de espécies pioneiras com ciclo de vida mais curto contribui para acelerar as taxas de dinâmica. Evidencias de diferenças nos padrões de composição de espécies entre os grupos são suportados pela redução dos valores de estresse da NMDS, com utilização de três dimensões e teste de PERMANOVA. Além disso, com maior abundância $(\mathrm{N})$, indicada pela PCA, é comum ocorrer alta mortalidade (NORDEN et al., 2015), sendo que o efeito do uso anterior do solo sobre a estrutura do solo e disponibilidade de nutrientes favorecem taxas demográficas menos estacionárias e mais estocásticas do que em florestas mais antigas (CHAZDON, 2014).

Algumas áreas com maior idade pósperturbação e com árvores de menor porte e área basal podem ser explicadas pela presença ou proximidade de clareiras, nas quais as mudanças são impulsionadas pela maior luminosidade e menor competição; e também estão sujeitas a um maior efeito da estocasticidade. O maior incremento das taxas é indicativo de uma fase de estruturação, 
desencadeada por perturbações passadas (SALAMI et al., 2014).

A relação direta da serapilheira com as taxas de dinâmica é tema pouco investigado até o momento. Os resultados indicam que, áreas com estrutura caracterizada por árvores médias e grandes, e com maior área basal, tiveram mudanças mais rápidas quando o acúmulo de serapilheira foi menor. Sugere-se que a decomposição da matéria orgânica é mais rápida nestes locais, já que essas florestas não diferem em relação à deposição de serapilheira (DICKOW et al., 2012; WOICIECHOWSKI, 2015). Como a decomposição é afetada pela diversidade taxonômica, diversidade funcional e composicional, e por alguns componentes ambientais (OLIVEIRA, MARQUES e MARQUES, 2019) e do microclima (luminosidade-temperatura, umidade, $\mathrm{pH}$, por exemplo), o aumento na diversidade de serapilheira e heterogeneidade espacial pode acelerar a taxa de ciclagem de nutrientes (CELENTANO et al., 2011). Neste sentido, em muitas florestas secundárias, a riqueza de espécies arbóreas supera aquela das florestas maduras (mais velhas), em função da coocorrência de espécies pioneiras que persistiram e não pioneiras que se estabeleceram (BONGERS et al., 2009).

Muita perturbação reduz a diversidade geral, mas a variedade de histórias de distúrbios locais contribui e maximiza a riqueza de espécies que pode ser mantida (BONGERS et al., 2009), melhorando a qualidade/diversidade da serapilheira. Soma-se à influência da maior diversidade, a menor relação $\mathrm{C} / \mathrm{N}$ na composição da serapilheira das espécies pioneiras que persistem, sendo de mais fácil decomposição. Como resultado, a ciclagem de nutrientes é rápida e o acumulo de matéria orgânica nos solos pode ser menor (LAVELLE et al., 2006), impulsionando o crescimento da vegetação e acelerando as taxas de dinâmica.

Os atributos químicos do solo apresentaram menor variabilidade nas amostras de solo subsuperficiais, pois os teores dos elementos no solo resultam, principalmente, da transformação do material de origem (rocha); enquanto que no solo superficial, a mineralização da matéria orgânica é quem comanda a composição química do solo. Nas três profundidades, $\mathrm{Ca}$ e Mn foram correlacionados com o eixo principal da PCA, e isso parece ser muito influenciado pela mineralização da serapilheira, uma vez que ela apresenta alta concentração desses nutrientes (WOICIECHOWSKI, 2015). Apesar disso, nem mesmo a ordenação dos atributos químicos da camada superficial foi eficiente para identificar áreas com diferentes taxas de dinâmica. Cruz et al. (2018) constataram que, dependendo da escala e do tamanho amostral, a dinâmica da floresta pode ser pouco influenciada por fatores ecológicos espacialmente estruturados, como no caso dos solos. As variações de concentrações de nutrientes da serapilheira, ao longo de um gradiente de perturbação, nem sempre são significativas, mesmo com uma mudança substancial na composição de espécies de plantas (PAUDEL et al., 2015).

As florestas estudadas estavam localizadas em encostas, mas as parcelas de estudo exibiram baixa amplitude da declividade. Já o padrão espacial apresentou alta variação (desvio padrão) dentro da mesma escala (Tabela 2). No entanto, ambos não se confirmaram como preditores da dinâmica florestal.

Destacamos neste artigo uma abordagem com interpolações das variáveis ambientais mapeadas e a extração destes valores para um atributo de cada árvore mapeada. Ao ponderar os valores médios da amostra, em função das árvores presentes e da localização que elas estão, obtém-se uma melhor simulação das condições naturais. Esta metodologia deve ser mais amplamente validada como alternativa aos métodos que utilizam a média aritmética simples.

\section{Conclusões}

Variações locais nos padrões dinâmicos das assembleias de árvores em vegetação secundária da Floresta Atlântica Submontana, no litoral do Paraná foram preditas 
satisfatoriamente por fatores bióticos (estrutura arbórea e quantidade de serapilheira acumulada). Sequencialmente, não sendo possível distinguir áreas com diferentes produtividades utilizando apenas dados da estrutura arbórea (diâmetro máximo, altura máxima e área basal), a serapilheira acumulada pode ser um bom indicador.

As evidências da relação da serapilheira para predizer mudanças demográficas de florestas tropicais em processo de sucessão secundária, precisam ser testadas em florestas plantadas e em outras florestas tropicais impactadas em regiões diferentes às deste estudo, considerando que tais resultados são promissores, com baixo custo e esforço de coleta.

\section{Agradecimentos}

Os autores agradecem à Sociedade de Pesquisa em Vida Selvagem e Educação Ambiental (SPVS) e ao Earthwatch Institute por disponibilizar recursos. Nossos agradecimentos também a todos àqueles que ajudaram na coleta de dados de campo e na revisão do artigo. $\mathrm{O}$ presente trabalho foi realizado com o apoio da Coordenação de Aperfeiçoamento de Pessoal de Nível Superior - Brasil (CAPES) - Processo: 1497765.

\section{Referências}

BADDELEY, A.; RUBAK, E.; TURNER, R. Spatial Point Patterns: Methodology and Applications with R. London, 2015.

BANKS-LEITE, C. et al. Using ecological thresholds to evaluate the costs and benefits of set-asides in a biodiversity hotspot. Science, v. 345, n. 1041, p. 1041-1045, 2014.

BONGERS, $F$. et al. The intermediate disturbance hypothesis applies to tropical forests, but disturbance contributes little to tree diversity. Ecology Letters, v. 12, n. 8, p. 798-
805, 2009.

CARDOSO, F. C. G. et al. Stem growth and phenology of two tropical trees in contrasting soil conditions. Plant and Soil, v. 354, n. 1-2, p. 269-281, 2012.

CELENTANO, D. et al. Litterfall dynamics under different tropical forest restoration strategies in Costa Rica. Biotropica, v. 43, n. 3, p. 279-287, 2011.

CHAZDON, R. L. Tropical forest recovery: Legacies of human impact and natural disturbances. Perspectives in Plant Ecology, Evolution and Systematics, v. 6, n. 1-2, p. 5171, 2003.

CHAZDON, R. L. Second Growth: The Promise of Tropical Forest Regeneration in an Age of Deforestation (University of Chicago Press, 2014).

CHEUNG, K. C.; MARQUES, M. C. M.; LIEBSCH, D. Relação entre a presença de vegetação herbácea e a regeneração natural de espécies lenhosas em pastagens abandonadas na Floresta Ombrófila Densa do Sul do Brasil. Acta Botanica Brasilica, v. 23, n. 4, p. 10481056, 2009.

CRUZ, A. P. et al. Inter-relação entre paisagem, organização florístico-estrutural e demografia do componente arbóreo em Floresta com Araucárias. Ciência Florestal, v. 28, n. 1, p. 6779, 2018.

DE'ATH, G. Multivariate Regression Trees : A New Technique for Modeling SpeciesEnvironment Relationships. Ecology, v. 83, n. 4, p. 1105-1117, 2002.

DICKOW, K. et al. Produção de serapilheira em diferentes fases sucessionais de uma floresta subtropical secundária em Antonina, PR. Cerne, v. 18, n. 1, p. $75-86,2012$.

DONHA, C. G. Dinâmica de crescimento e estoque de biomassa, carbono e nutrientes em 
espécies arbóreas da Floresta Atlântica no Sul do Brasil. 2016. 205p. Tese (Doutorado em Engenharia Florestal) - Universidade Federal do Paraná. 2016. https://acervodigital.ufpr.br/handle/1884/52644

FERRETTI, A. R.; BRITEZ, R. M. Ecological restoration, carbon sequestration and biodiversity conservation: The experience of the Society for Wildlife Research and Environmental Education (SPVS) in the Atlantic Rain Forest of Southern Brazil. Journal for Nature Conservation, v.14 (3), 249-259, $2006 . \quad$ Disponível em: <https://doi.org/10.1016/j.jnc.2006.04.006>.

GROSS, A. et al. Fragmentation as a key driver of tree community dynamics in mixed subtropical evergreen forests in Southern Brazil. Forest Ecology and Management, v. 411, p. 20-26, 2018. Disponível em: <https://doi.org/10.1016/j.foreco.2018.01.013>.

HIGUCHI, P. forest.din: Função em linguagem de programação estatística $R$ para a determinação de taxas demográficas de espécies arbóreas.

2017

https://doi.org/10.5281/zenodo.439701.

HOTHORN, T.; HORNIK, K.; ZEILEIS, A. Unbiased recursive partitioning: A conditional inference framework. Journal of Computational and Graphical Statistics, v. 15, n. 3, p. 651-674, 2006.

LAVELLE, P. et al. A Hierarchical Model for Decomposition in Terrestrial Ecosystems: Application to Soils of the Humid Tropics. Biotropica, v. 25, n. 2, p. 130-150, 1993.

LAVELLE, P. et al. Soil invertebrates and ecosystem services. European Journal of Soil Biology, v.42, p.S3-S15, 2006.

MACHADO, E. L. M.; OLIVEIRA-FILHO, A. T. Spatial patterns of tree community dynamics are detectable in a small (4 ha) and disturbed fragment of the Brazilian Atlantic forest. Acta Botanica Brasilica, v. 24, n. 1, p. 250-261,
2010.

MARQUES, M. C. M. et al. Dynamics and diversity of flooded and unflooded forests in a brazilian atlantic rain forest: A 16-year study. Plant Ecology and Diversity, v. 2, n. 1, p. 5764, 2009.

MARTINS, K. G. et al. Effects of soil conditions on the diversity of tropical forests across a successional gradient. Forest Ecology and Management, v. 349, p. 4-11, 2015. Disponível em: < http://dx.doi.org/10.1016/j.foreco.2015.04.018

NORDEN, N. et al. Successional dynamics in Neotropical forests are as uncertain as they are predictable. Proceedings of the National Academy of Sciences, v. 112, n. 26, p. 80138018, 2015.

OKSANEN, J. et al. vegan: Community Ecology Package. $\mathrm{R}$ package version 2.5-4. $2019 . \quad$ https://CRAN.Rproject.org/package=vegan

OLIVEIRA, R. A. C.; MARQUES, R.; MARQUES, M. C. M. Plant diversity and local environmental conditions indirectly affect litter decomposition in a tropical forest. Applied Soil Ecology, v. 134, p. 45-53, 2019. Disponível em:

<https://doi.org/10.1016/j.apsoil.2018.09.016>.

PAUDEL, E. et al. Litterfall and nutrient return along a disturbance gradient in a tropical montane forest. Forest Ecology and Management, v. 353, p. 97-106, 2015.

R CORE TEAM (2019). R: A language and environment for statistical computing. $\mathrm{R}$ Foundation for Statistical Computing, Vienna, Austria. URL https://www.R-project.org/.

REZENDE, C. L. et al. From hotspot to hopespot: An opportunity for the Brazilian Atlantic Forest. Perspectives in Ecology and Conservation, v. 16, n. 4, p. 208-214, 2018. Disponível em: 
<https://doi.org/10.1016/j.pecon.2018.10.002>.

RIBEIRO, M. C. et al. The Brazilian Atlantic Forest: How much is left, and how is the remaining forest distributed? Implications for conservation. Biological Conservation, v. 142, n. 6, p. 1141-1153, 2009. Disponível em: $<$ http://dx.doi.org/10.1016/j.biocon.2009.02.02 $1>$. .

SALAMI, B. et al. Influência de variáveis ambientais na dinâmica do componente arbóreo em um fragmento de Floresta Ombrófila Mista em Lages, SC. Scientia Forestalis, v. 42, n. 102, p. 197-207, 2014.

VITOUSEK, P. M.; HOWARTH, R. W. Nitrogen Limitation on Land and in the Sea: How Can It Occur? Biogeochemistry, v. 13, n. 2, p. 87-115, 1991.

WOICIECHOWSKI, T. Ciclagem de fitomassa e nutrientes na Floresta Ombrófila Densa Submontana no litoral do Paraná. Programa de Pós-Graduação em Engenharia Florestal, 2015. Universidade Federal do Paraná. 